\title{
Towards A Genetic Model Organism: An Efficient Method For Stable Genetic Transformation of Eschscholzia Californica (Ranunculales)
}

\section{Dominik Lotz}

Justus Liebig Universitat Giessen

Jafargholi Imani

Justus Liebig Universitat Giessen Fachbereich fur Agrarwissenschaften Okotrophologie und Umweltmanagement

Katrin Ehlers

Justus Liebig Universitat Giessen

Annette Becker ( $\nabla$ annette.becker@bot1.bio.uni-giessen.de )

Justus-Liebig-University https://orcid.org/0000-0002-3229-2162

\section{Research Article}

Keywords: Eschscholzia californica, Ranunculales, Papaveraceae, transformation, protoplasts

Posted Date: September 9th, 2021

DOI: https://doi.org/10.21203/rs.3.rs-805216/v1

License: (c) (i) This work is licensed under a Creative Commons Attribution 4.0 International License. Read Full License 


\section{Abstract}

California poppy (Eschscholzia californica) is a member of the Ranunculales, the sister order to all other eudicots and as such in a phylogenetically highly informative position. Ranunculales are known for their diverse floral morphologies and biosynthesis of many pharmaceutically relevant alkaloids. E. californica it is widely used as model system to study the conservation of flower developmental control genes. However, within the Ranunculales, options for stable genetic manipulations are rare and genetic model systems are thus difficult to establish. Here, we present a method for the efficient and stable genetic transformation via Agrobacterium tumefaciens-mediated transformation, somatic embryo induction, and regeneration of E. californica. Further, we provide a rapid method for protoplast isolation and transformation. This allows the study of gene functions in a single-cell and full plant context to enable gene function analysis and modification of alkaloid biosynthesis pathways by e.g. genome editing techniques providing important genetic resources for the genetic model organism E. californica.

\section{Introduction}

The order Ranunculales holds a key position in the phylogenetic tree of angiosperms, because it is the sister lineage to all extant eudicots (APG IV 2016). Ranunculales emerged approx. 130 Million years ago (Magallón et al. 2015) and are characterized by a large diversity in life-history traits, growth habit, leaf shape, flower and fruit forms, etc. - the flowers of Ranunculales in particular are extremely diverse (Damerval and Becker 2017). Besides their stunning floral morphology, they are also extremely diverse in the production of economically valuable benzylisoquinoline alkaloids (BIAs). Around 2500 BIAS have been identified, with the major BIAs being morphine (analgesic), noscapine (anticancer drug), papaverine (spasmolytic), and sanguinarine (antibacterial), and they are predominantly found in Ranunculales (Dastmalchi et al. 2018).

E. californica was developed as a model organism for the analysis of BIA metabolism and its regulation and to study the evolution and functional conservation of key regulators of flower development. Several flower developmental regulators were analyzed already by Virus-Induced Gene Silencing (Wege et al. 2007) providing a comprehensive view on the regulation of floral morphogenesis in E. californica and the conservation of the flower developmental program in dicots (Orashakova et al. 2009; Lange et al. 2013; Wreath et al. 2013; Zhao et al. 2018; Zhou et al. 2018). However, VIGS was adopted in many Ranunculales (Damerval and Becker 2017), but it is a transient method and produces sectors with differing gene expression, is often not heritable (Dommes et al. 2019), and a mean to generate stable transgenic lines of E. californica is required by many researchers.

E. californica has provoked additional scientific interest because it is a highly invasive species. Native to mainly California, it has extended its range in regions of South America, Europe, and Australia with a Mediterranean climate (Stebbins. 1995; Peña-Gómez et al. 2014; Bustamante et al. 2017). Previous studies have shown that the fecundity of invasive populations of E. californica is higher than that of native populations, seeds persist in seed banks for years (Peña-Gómez et al. 2014; Hickman, 1993). These invasive populations are locally adapted and show a superior colonization ability (Leger and Rice 2007).

Within the Ranunculales, a high-quality genome is available for opium poppy (Papaver somniferum, Guo et al. 2018). In addition, draft genomes are available for several Ranunculales members such as Eschscholzia californica and Macleaya cordata of the Papaveraceae family and Aquilegia coerulea of the Ranunculaceae family (Liu et al. 2017; Hori et al. 2018; Filiault et al. 2018). These provided the base for the reconstruction of the evolutionary history of enzymes involved in BIA biosynthesis (Li et al. 2020). E. california's major BIAs are (S)-reticuline, berberine, and sanguinarine, however, it lacks the enzymes necessary to synthesize noscapine and morphine (Li et al. 2020; Balažová et al. 2020). Several regulators of the BIA biosynthesis (Yamada et al. 2017) or parts of the biosynthesis pathway of isoquinoline 
alkaloids area have been described, but insights in BIA and isoquinoline alkaloid biosynthesis and their regulation were mostly obtained by analyses utilizing suspension cultures (Yamada et al. 2017; Balažová et al. 2020) and lack information on regulation of alkaloid biosynthesis obtained from fully grown transgenic plants of $E$. californica. A detailed protocol for suspension cultures of E. californica was established previously (Park und Facchini 2000a), where culture conditions were optimized by investigating the effect of different phytohormones and component. (Park und Facchini 2000) reported a protocol to generate stable transgenics as well, but no further research was published using this protocol.

In Ranunculales species, reliable protocols for stable genetic transformation and subsequent regeneration of mature plants do not exist, with the exception of Papaver somniferum (Yoshimatsu und Shimomura 1992; Chitty et al. 2003; Park und Facchini 2000a). Here, we present a simple and efficient protocol for the isolation and transformation of $E$. californica protoplasts and the optimization of methods for plant regeneration, transformation, and generation of stable transgenic E. californica plants differing from Park and Facchini (1999) in several aspects. This provides an important step towards gene function analysis in E. californica, allowing the testing of hypothesis especially in the field of evodevo and BIA metabolism and its regulation.

\section{Material And Methods}

\section{Plant culture, protoplast isolation and transformation}

All methods described here are documented in a detailed step-by-step protocol including a trouble shooting guide (online resource 3).

To test vectors used for stable genetic transformation, a protoplast system can very useful because it provides preliminary data fast. For example, different CRISPR-Cas9 constructs can be tested in the protoplast system for their genome editing efficiency. Firstly, protoplasts were isolated from cotyledons and hypocotyl of seedlings grown in sterile conditions. E. californica seeds (cv. Aurantiaca Orance King, B\&T World Seeds, Aigues-Vive, France) were surface sterilised (see Supplemental Protocol for a detailed step-to-step protocol) and sown on solid full strength Gamborg B5 medium including vitamins (B5, for a detailed composition of all media, see Supplemental Material 3) supplemented with $1 \%$ sucrose and $1 \%$ Gelrite (Duchefa Biochemie, Haarlem, The Netherlands) and maintained in sterile conditions for the entire procedure. The seeds were germinated at $25^{\circ} \mathrm{C}$ under long day conditions (16 hours of light, light intensity $\left.95 \mu \mathrm{mol} \mathrm{m} \mathrm{m}^{-2} \mathrm{~s}^{-1}\right)$. The cotyledons and hypocotyls of 10-days-old seedling were used for protoplast isolation based on Shan et al. (2014) with the following modifications: about $2 \mathrm{~g}$ of tissue was sliced into thin strips and incubated in 0.6 $\mathrm{M}$ mannitol solution for plasmolysis at RT for $10 \mathrm{~min}$ and transferred to $50 \mathrm{ml}$ enzyme solution, and vacuum infiltrated (350 $\mathrm{mmHg}$ ) for $30 \mathrm{~min}$ in the dark respectively. After $4 \mathrm{~h}$ of incubations in the dark with $70 \mathrm{rpm}$ shaking at RT, the mixture was filtered through a $100 \mu \mathrm{m}$ nylon mesh and pelleted by centrifugation at $300 \mathrm{~g}$ for $3 \mathrm{~min}$, and resuspended in $10 \mathrm{ml}$ of W5 solution including $2 \mathrm{mM}$ MES (pH 5.7) containing $154 \mathrm{mM} \mathrm{NaCl}, 125 \mathrm{mM} \mathrm{CaCl}$ and $5 \mathrm{mM} \mathrm{KCl}$. Then protoplasts were pelleted at $300 \mathrm{~g}$ for 3 min and resuspended in $4 \mathrm{ml}$ of mannitol $\mathrm{MgCl}_{2}(\mathrm{MMG})$ solution. Protoplast density was counted by hemocytometry (described in more detail in online resource 3 ).

For protoplast transformation, the working density of the protoplasts was adjusted to $5 \times 10^{5}$ protoplasts per $\mathrm{ml}$ with MMG solution. PEG-mediated transformation with the vector pGGZ003 pro35S:Omega:GFP-

NLS:Dummy:TerRBCS;pMAS:BASTA:tMAS carrying 35S:GFP was performed as described in Liang et al. 2018 with the following modifications: after the mixture was incubated for $20 \mathrm{~min}$ in the dark, the protoplasts were centrifuged at 300 $\mathrm{g}$ for $3 \mathrm{~min}$. Following transformation, the protoplasts were incubated for about $64 \mathrm{~h}$ at $23^{\circ} \mathrm{C}$ in the dark. Fluorescence was examined with a Leica DM5500B microscope, a Leica DFC450 camera and the Leica L5 FL Cold Light Fluorescence System Leica Filter Cube: L5. Photos were arranged by the Inkscape 1.0 software (Inkscape Developers, 2020). 


\section{Callus regeneration and stable genetic transformation}

Plant regeneration and transformation was optimized by analyzing several variables in the previously published protocol (Park and Facchini 2000), for example hormone type and concentration, carbohydrate composition, or the use of activated charcoal based on literature research. The optimized protocol commences with plant germination, where surface sterilised E. californica seeds were used. Hypocotyls of 10 days old plants were used to induce callus growth on solid callus induction medium including full strength MS + vitamins (Supplemental Material 3), $6 \%$ sucrose, $1.6 \%$ Phytoagar, 1 mg/l 2.4-Dichlorophenoxyacetic acid (2.4-D), 5 replicates were analysed and consisted of three seedlings each, of which the hypocotyl was sliced into 1-2 cm parts. Callus formation required three to four weeks. To be sure that all possible calli can develop, the calli grow for four to six weeks in total and were then transferred to somatic embryo induction medium including full strength B5 powder, 6\% sucrose, 1.6\% Phytoagar, $1 \mathrm{mg} / \mathrm{l}$ 1-Naphthaleneacetic acid (NAA), $0.5 \mathrm{mg} / \mathrm{l}$ 6-Benzylaminopurine (BAP), to generate somatic embryos after six to eight weeks. Somatic embryos were transferred to maturation medium including full strength $B 5,6 \%$ maltose, $1.6 \%$ Phytoagar, for 21 days. Subsequently, the somatic embryos were transferred to plant regeneration medium including full strength B5 powder, $6 \%$ sucrose and $1 \%$ Gelrite. Regenerated plantlets were transferred to soil and grown under long day conditions (16 hours of light, light intensity $\sim 95 \mu \mathrm{mol} \mathrm{m} \mathrm{m}^{-2} \mathrm{~s}^{-1}$ at $22^{\circ} \mathrm{C}$ ).

During the optimization process of the plant regeneration protocol, different concentrations of media components were compared to find the optimal conditions. We analyzed the influence of different auxins of different concentrations: 2.4-D with a concentration of $0.5 \mathrm{mg} / \mathrm{l}$ up to $3 \mathrm{mg} / \mathrm{l}$ were compared with $2 \mathrm{mg} / \mathrm{I}$ NAA in combination with $0.1 \mathrm{mg} / \mathrm{l} \mathrm{BAP}$. The capacity of cotyledons, hypocotyl, unripe seeds, somatic embryos but also root tissues for suitability as explant were analyzed by incubation for four weeks on callus induction medium. To get rid of the huge number of secondary metabolites within poppy plants, different combinations of activated charcoal was tested. Next to the optimization, another step was added to the regeneration process. Embryo maturation was performed by analyzing the influence of 3 $\mathrm{g} / \mathrm{l}$ Maltose, $2.5 \mathrm{mg} / \mathrm{I} \mathrm{ABA}, 4 \mathrm{~g} / \mathrm{l}$ PEG compared with plant regeneration medium.

Susceptibility to antibiotics was analysed with a kill curve: E. californica calli were transferred to selection medium supplemented with various concentrations of Hygromycin B ( $5 \mathrm{mg} / \mathrm{l}, 10 \mathrm{mg} / \mathrm{l}, 20 \mathrm{mg} / \mathrm{l}, 30 \mathrm{mg} / \mathrm{l}, 40 \mathrm{mg} / \mathrm{l})$ for four weeks and visually analysed. For removal of remaining Agrobacteria and other potential infectious agents, callus induction medium and somatic embryo induction medium included 200mg/l Cefotaxime.

To optimize the efficiency of plant transformation, different tissues were analysed with Agrobacterium tumefaciens mediated transformation, with callus tissue being most susceptible. Callus tissues was immersed in $A$. tumefaciens strain GV3101 carrying a p35S:GFP cassette included in the vector pGGZ003_p35S:GFP_HygR suspension (with an $\mathrm{OD}_{600}$ of 1.0) for 20 min with mild shaking. Then, callus tissue was transferred to callus induction medium for cocultivation with $A$. tumefaciens for two days in the dark, and then moved to callus induction medium with $200 \mathrm{mg} / \mathrm{l}$ Cefotaxime added. Subsequently after four weeks, the calli were transferred to callus induction medium supplemented with $200 \mathrm{mg} / \mathrm{l}$ Cefotaxime and $40 \mathrm{mg} / \mathrm{l} \mathrm{Hygromycin} \mathrm{and} \mathrm{grown} \mathrm{for} \mathrm{four} \mathrm{weeks} \mathrm{on} \mathrm{selective} \mathrm{medium.} \mathrm{Resistant} \mathrm{calli} \mathrm{were}$ transferred to somatic embryo induction medium, and treated similarly as described above for non-transformed plants. Somatic embryo induction was supplemented with 200 mg/l Cefotaxime and 40 mg/l Hygromycin.

\section{Vector cloning}

The GFP reporter vectors pGGZ003pro35S:GFP:HygR and pGGZ003 pro35S:Omega:GFP-

NLS:Dummy:TerRBCS;pMAS:BASTA:tMAS were constructed using the Greengate system based on the vector pGGZ003 (Lampropoulos et al. 2013). A reaction containing $150 \mathrm{ng}$ of each module (pro35S: $\Omega$ :GFP:Dummy:TerRBCS;

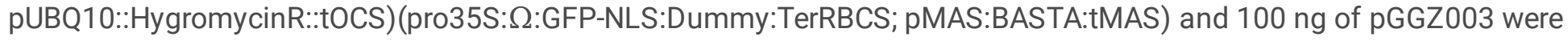


set up according to Lampropoulos et al. 2013. Chemocompetent $E$. coli DH5a cells were transformed with $4 \mu$ l reaction mix to amplify the construct. The correct assembly was monitored by sequencing and the vector was isolated and introduced in A. tumefaciens strain GV3101 by electroporation following standard protocols.

\section{Western blot analysis}

Tissue from putatively transgenic E. californica plants was collected from different developmental stages (callus, somatic embryos, young regenerated plants) during plant regeneration. Material was frozen in liquid nitrogen and ground using a tissue-lyser. The sample was then mixed with pre-heated 4x Laemmli buffer (100 $\mu$ l/200 mg sample containing $30 \mathrm{mg} / \mathrm{ml} \mathrm{DDT}$ ). After $5 \mathrm{~min}$ at $100^{\circ} \mathrm{C}$, the samples were centrifuged at $14000 \mathrm{rpm}$ for one minute and $30 \mu \mathrm{l}$ of the supernatant was loaded on a 12\% SDS gel. PageRuler Prestained Protein Ladder (Thermo Fischer, Langenselbold, Germany) was used as a marker. After $30 \mathrm{~min}$ at $80 \mathrm{~V}$ followed by $2 \mathrm{~h}$ at $100 \mathrm{~V}$ ) the gel was transferred to a PVDF membrane. The samples were blocked with $1 \%$ BSA in TBS buffer + Tween for 2 hours and incubated with an AntiGreen Fluorescent Protein - Horseradish Peroxidase (Miltenyi Biotec, Bergisch Gladbach, Germany) (GFP-HRP) antibody $1: 8000$ in $2.5 \%$ BSA overnight at $4^{\circ} \mathrm{C}$ with shaking. After the incubation, the gel was washed three times for 10 min each in TBS-T (0.1\% TWEEN20) solution. To detect the proteins, $500 \mu$ of Amersham ECL Western Blotting Detection Reagent (1:1 solution A and solution B, Amersham, Freiburg, Germany) was used. Images were created using a ChemiDOC MP Imaging System (Biorad, Neuberg, Germany).

\section{Results And Discussions}

\section{Protoplast isolation and transformation}

Many experimental approaches, such as biochemical, protein-protein or protein-DNA interaction analyses do not require fully-grown plants and protoplasts are suitable experimental systems. We thus developed a protocol for rapid protoplast isolation and transformation (online resource 3, step-by-step protocol). Protoplasts were isolated from the leaf and hypocotyl tissue of 10 days old in vitro grown plants using macerozyme and cellulose R10 to digest cell walls. The protoplast isolation yielded between 0.45 and $0.85 \times 10^{6}$ protoplasts / g plant tissue. These protoplasts were round, only occasionally was the cell wall still attached, and they included many chloroplasts (Fig. $1 \mathrm{~A}$ and B).

Next, we transformed the freshly isolated protoplasts with a nuclear localized, ubiquitously expressed GFP protein as fluorescent marker driven by CaMV 35S promoter (p35:GFP:NLS). Employing a PEG-mediated transformation protocol, the transformation efficiency was between $13.5 \%$ and $24.8 \%$ (Fig. 1C). The transformation efficiency is dependent on the incubation time of the enzyme solution, such that an incubation time of $1.5 \mathrm{~h}$ yielded $11.8 \%$ transformed protoplasts and 4 h $24.8 \%$ transformed protoplasts (Fig. 1D). Incompletely digested cell walls may thus inhibit the PEG-mediated transformation. Nuclear localized GFP signal was detected using fluorescent microscopy $64 \mathrm{~h}$ post transformation (Fig. E-G). Protoplasts were visually unchanged (Fig. 1E) when compared to freshly isolated protoplasts (Fig. 1A) suggesting that the transformation and subsequent incubation time had no obvious negative effect on protoplast viability. The protoplasts showed a very low level of auto fluorescence (Fig. 1F). Suppl. Figure 2 provides a flowchart summarizing the experimental steps for protoplast transformation and all other approaches described here (Online Resource 1, Fig. 1).

\section{Plant regeneration from explants}

Establishing E. californica as a genetic model plant requires the possibility for stable transformation and thus we developed a reliable, tissue-culture based method for plant regeneration as a first step towards a transformation protocol (Online Resource 1, Fig. 1). 
We first analyzed the type of explant, and type and concentration of auxin best suitable for callus regeneration of $E$. califonica (Table 1). Using 2.4-D as auxin source resultsed in all used concentration in callus regeneration, with hypocotyl being more amenable to callus regeneration. A concentration of $1 \mathrm{mg} / \mathrm{l} 2.4-\mathrm{D}$ was sufficient for regeneration of callus tissue from every explant. After four weeks, almost all hypocotyl explants regenerated callus ( $97.8 \%)$ that were subsequently induced to develop somatic embryos (Online Resource 2, Tables 1 and 2). After seven weeks, 44\% of the calli produced somatic embryos and after this time, only marginally more calli generated somatic embryos (Online Resource 2, Table 2). The somatic embryos were removed from the calli and matured for three weeks (Online Resource 2 , Table 3) on a specific maturation medium including maltose instead of sucrose and subsequently, they were kept in the light until they turned green and commenced organogenesis. From 58\% of the somatic embryos, plantlets could be regenerated, and $60 \%$ of these plantlets developed into fully grown plants in soil (Online Resource 2, Tables 3 to 5). The regenerated plantlets were transferred to soil after four to six weeks (Online Resource 2, Table 6). The surviving plants formed morphologies similar to plants grown from seeds and were fully fertile. Generally, the regeneration of $E$. californica plants was carried out in at least five repititions.

Taken together, we established an efficient E. californica in vitro plant regeneration protocol, from hypocotyl explants to mature plants via callus induction and somatic embryogenesis. Figure 2 shows an overview of the time scale of $E$. californica regeneration.

\section{Optimization of the plant regeneration protocol}

To obtain an efficient and reproducible protocol for E. californica transformation, several modifications to the transformation protocol reported earlier (Park and Facchini 2000b) were tested. For example, the addition of $2.0 \mathrm{mg} / \mathrm{l}$ NAA and $0.1 \mathrm{mg} / \mathrm{l}$ BAP to the callus induction medium was replaced by adding only $1 \mathrm{mg} / \mathrm{l} 2,4 \mathrm{D}$, which raised the number of explants producing calli to nearly $100 \%$ (Table 1). Further, we analyzed if cotyledons or hypocotyl produced callus material more reliably and found that with the optimal concentration of $1 \mathrm{mg} / \mathrm{l} 2,4-\mathrm{D}$, all hypocotyl explants produced callus while only max. $80 \%$ of the cotyledon explants produced calli (with an optimal 2,4-D concentration of $1,5 \mathrm{mg} / \mathrm{l}$, Table 1). Next we analysed if unripe seeds (21 days after polination) have the potential to regenerate callus. We compared $1 \mathrm{mg} / \mathrm{l}$ 2.4-D with $2 \mathrm{mg} / \mathrm{I} \mathrm{NAA}$ and $0.1 \mathrm{mg} / \mathrm{l} \mathrm{BAP}$ and our results show that unripe seeds have a lower callus regeneration rate than cotelydons and hypocotyl, independend of the auxin source (Table 1). We also analyzed if reducing cell culture inhibitory secondary metabolites by adding $0,5 \mathrm{~g} / \mathrm{l}$ activated charcoal to the cell culture medium improves callus formation (Möller et al. 2006; Thomas 2008). However, the callus regeneration from hypocotyl dropped from 100-33\% when charcoal was added (Table 1), suggesting that charcoal may block phytohormone activity. Additionally, we analysed if somatic embryos can dedifferentiate to callus by adding $1 \mathrm{mg} / \mathrm{l} 2.4-\mathrm{D}$ or $2 \mathrm{mg} / \mathrm{I} \mathrm{NAA}, 0.1$ $\mathrm{mg} / \mathrm{I}$ BAP and activated charcoal. 2.4-D leads to new callus regeneration in more than $90 \%$. Interestingly, the combination of NAA, BAP and activated charcoal leads to the regeneration of new somatic embryos within six weeks in nearly $100 \%$ of all samples (Table 1). Finally, a somatic embryo maturation phase was introduced to the protocol to improve greening and proper morphogenesis of the embryos. We analyzed several combinations of maltose, PEG and abscisic acid (ABA), and found that exchanging sucrose as carbon source with $3 \%$ maltose alone performed best, with around $84 \%$ of the embryos started photosynthesis in contrast to a combination of $3 \%$ maltose with $2.5 \mathrm{mg} / \mathrm{l}$ ABA which

killed around $97 \%$ of the calli (Online Resource 2, Table 3). In addition, the regenerated plants grew better in plain standard soil; around $80 \%$ survived the transfer from in vitro culture to soil when compared to vermiculite as substrate, which only around $54 \%$ of the plants survived (Online Resource 2 , Table 6).

Agrobacterium -mediated transformation of E. californica

Based on the tissue culture and regeneration method described earlier, we developed an efficient transformation protocol using E. californica hypocotyl as explant and employing Agrobacterium tumefaciens based transformation to 
generate transgenic lines carrying the reporter construct $p 35 S$ ::GFP using hygromycin as selectable marker. A killingcurve experiment showed that a concentration of $40 \mathrm{mg} / \mathrm{l}$ hygromycin is sufficient to select transgenic plants (Online Resource 1, Fig. 2; Online Resource 2, Table 7). The transgenic calli produced somatic embryos, which were then regenerated into fully grown, fertile plants employing the plant regeneration protocol (online resource 1, Fig. 3). Figure 3 (A-P) shows mock-treated and 35S:GFP treated calli and somatic embryos in bright field and fluorescence microscopy. Only a small fraction of callus cells is transformed and has already started to divide (Fig. 3A to H). Those will later provide the transgenic calli shown in Fig. $3 \mathrm{~L}$ and $\mathrm{P}$, while the untransformed cells of the calli discontinue division and die eventually. Healthy calli under selection are then removed and incubated on somatic embryo induction medium. Wild type calli regenerating somatic embryos are shown in Fig. $3 \mathrm{I}, \mathrm{J}, \mathrm{M}$, and N). Figure $3 \mathrm{~K}, \mathrm{~L}, \mathrm{O}$, and P show two fully fluorescent calli that are derived from transformation events. Those generate genetically identical somatic embryos that are also completely fluorescent, showing that the $35 \mathrm{~S}$ promoter is active in callus tissue and somatic embryos. The presence of transgenic GFP protein in the transformed tissues was corroborated by Western blot analysis (Fig. 3Q). In total, 23 independently transformed transgenic calli were derived that, when cultured on somatic embryo induction medium, all continuously produced genetically identical somatic embryos. A strong GFP signal was detected in $65 \%$ of the regenerated somatic embryos (Fig. 3 and Online Resource 2, Table 8).

Unexpectedly, the mock-treated calli and somatic embryos also show a faint fluorescence (Fig. 3B, F, J, N), but this is much lower in intensity than the GFP fluorescence in Fig. $3 \mathrm{C}, \mathrm{D}, \mathrm{G}, \mathrm{H}, \mathrm{L}$, and $\mathrm{P}$, and suggestive of fluorescing secondary metabolites. Interestingly, it was shown previously, that E. californica suspension cultures produce benzophenanthridine alkaloids with an excitation of 270-550 nm and emissions at 310-590 nm (Hisiger and Jolicoeur 2005). Those lie within the range of the GFP excitation and emission spectrum (max. $488 \mathrm{~nm}$ and $507 \mathrm{~nm}$, respectively) and could explain the low intensity fluorescence observed in wild type calli and somatic embryos. $p 35 S$ :GFP transformed plants show a morphology similar to that of wild type plants that underwent tissue culture based regeneration, except for the flowers, which show folded mature petals in the transgenics (Online Resource 1, Fig. 3).

\section{Other E. californica transformation methods}

There are other means to generate transgenic E. californica tissue, for example by using biolistic bombardment of callus tissue (Popelka et al. 2003; Viehweger et al. 2006; Angelova et al. 2010), but this requires an expensive biolistic particle delivery system. Using the regeneration protocol reported here, this method can be extended to generated transgenic lines. Another protocol published earlier reports an approach similar to ours, but with different media/phytohormone compositions and paromomycin as plant resistance markers (Park and Facchini 2000b). However, this method is less efficient in terms of callus generation from explants, for example, with our method, around $98 \%$ of explant generate calli, with the previous protocol only $80 \% .30 \%$ of the calli then generated somatic embryos within three to four weeks, while using the method reported here, nearly $45 \%$ of calli developed somatic embryos within seven weeks, indicating that our protocol is more efficient than the previous one. Further, the somatic embryo induction medium we used induced continuous production of somatic embryos from transgenic calli, such that up to 37 transgenic calli could be subcultured from a single callus (Online Resource 2, Table 10). Unfortunately, we cannot compare our work with how the method by Park and Facchini (2000b) performs in other labs, as no further work based on this protocol was published.

\section{Conclusions}

The possibility to create stable transgenics is the prerequisite to establish E. californica as a genetic model system for the Ranunculales, the sister order to the core eudicots. Other practical aspects such as a short generation cycle of only two months from seed to flower, undemanding growing conditions, and a comparatively small genome of only six times that of Arabidopsis thaliana add to the value of the model species E. californica (Becker et al. 2005; Wege et al. 2007; Yamada et al. 2021). Our work provides efficient means for gene function analysis in E. californica using stable 
transgenic lines to generate reproducible results. Approaches like CRISPR-Cas9 mediated genome modifications, reporter lines for phytohormones detection, or stable and localized modifications of alkaloid biosynthesis(Alagoz et al. 2016; Isoda et al. 2021; Hayashi et al. 2020) are facilitated by the work reported here. Researchers interested in alkaloid biosynthesis and regulation may work with E. californica without specific permits as they are required for $P$. somniferum. For example, E. californica is a promising model species to study the mutual influence of development and alkaloid biosynthesis(Yamada et al. 2020) or to analyse flower evolution on the molecular level (Zhao et al. 2018). Taken together, our work provides an important step towards the establishment of E. californica as a genetic model system to study a large suite of diverse research questions.

\section{Abbreviations}

\section{2,4 D: 2,4-Dichlorophenoxyacetic acid}

35S: 35 Svedberg Units DNA fragment of the Cauliflower Mosaic Virus promoter region

BAP: 6-Benzylaminopurine

BIA: benzylisoquinoline alkaloids

GFP: GREEN FLUORESCENT PROTEIN

NAA: 1-Naphthaleneacetic acid

pUBQ10: promoter of the UBIQUITIN 10 gene of Arabidopsis thaliana

VIGS: Virus-Induced-Gene-Silencing

\section{Declarations}

\section{Funding: This work was funded by the Justus-Liebig-University Gießen, Germany}

Conflicts of interest/Competing interests: There are no conflicts of interest or competing interests

Availability of data and material: vectors and seeds of transgenic lines may be obtained from the corresponding author.

Code availability: n.a.

Authors' contributions: DL, KE and $\mathrm{JI}$ carried out experiments and analysed the data; $\mathrm{JI}$ and $\mathrm{KE}$ gave input in experimental design and helped with microscopy; $A B$ supervised experiments and wrote the manuscript. All authors read and approved the final version of the manuscript.

Ethics approval: n.a.

Consent to participate: n.a.

Consent for publication: n.a.

\section{Acknowledgements}


We thank Dietmar Haffer for his expertise and help in transferring the in vitro grown plants to soil, Thomas Groß for constructing the vector carrying the 35S:GFP cassette and Martina Claar for support with the Western blot. The student Verena Gisa helped with tissue culture.

\section{References}

1. Alagoz, Yagiz; Gurkok, Tugba; Zhang, Baohong; Unver, Turgay (2016): Manipulating the Biosynthesis of Bioactive Compound Alkaloids for Next-Generation Metabolic Engineering in Opium Poppy Using CRISPR-Cas 9 Genome Editing Technology. In: Scientific reports 6, S. 30910. DOI: 10.1038/srep30910.

2. An update of the Angiosperm Phylogeny Group classification for the orders and families of flowering plants: APG IV (2016). In: Bot. J. Linn. Soc. 181 (1), S. 1-20.

3. Angelova, Sornitza; Buchheim, Marcus; Frowitter, Doreen; Schierhorn, Angelika; Roos, Werner (2010): Overproduction of alkaloid phytoalexins in California poppy cells is associated with the co-expression of biosynthetic and stressprotective enzymes. In: Molecular plant 3 (5), S. 927-939. DOI: 10.1093/mp/ssq043.

4. Balažová, Andrea; Urdová, Júlia; Forman, Vladimír; Mučaji, Pavel (2020): Enhancement of Macarpine Production in Eschscholzia Californica Suspension Cultures under Salicylic Acid Elicitation and Precursor Supplementation. In: Molecules (Basel, Switzerland) 25 (6). DOI: 10.3390/molecules25061261.

5. Becker, Annette; Gleissberg, Stefan; Smyth, David R. (2005): Floral and Vegetative Morphogenesis in California Poppy (Eschscholzia californica Cham.). In: International Journal of Plant Sciences 166 (4), S. 537-555. DOI: $10.1086 / 429866$.

6. Bustamante, Ramiro 0.; Durán, América P.; Peña-Gómez, Francisco T.; Véliz, David (2017): Genetic and phenotypic variation, dispersal limitation and reproductive success in the invasive herb Eschscholzia californica along an elevation gradient in central Chile. In: Plant Ecology \& Diversity 10 (5-6), S. 419-429. DOI: 10.1080/17550874.2018.1425504.

7. Chitty, Julie A.; Allen, Robert S.; Fist, Anthony J.; Larkin, Philip J. (2003): Genetic transformation in commercial Tasmanian cultivars of opium poppy, Papaver somniferum, and movement of transgenicpollen in the field. In: Functional plant biology : FPB 30 (10), S. 1045-1058. DOI: 10.1071/FP03126.

8. Damerval, Catherine; Becker, Annette (2017): Genetics of flower development in Ranunculales - a new, basal eudicot model order for studying flower evolution. In: The New phytologist 216 (2), S. 361-366. DOI: 10.1111/nph.14401.

9. Dastmalchi, Mehran; Park, Myung Ryeol; Morris, Jeremy S.; Facchini, Peter (2018): Family portraits: the enzymes behind benzylisoquinoline alkaloid diversity. In: Phytochem Rev 17 (2), S. 249-277. DOI: 10.1007/s11101-0179519-z.

10. Dommes, Anna B.; Gross, Thomas; Herbert, Denise B.; Kivivirta, Kimmo I.; Becker, Annette (2019): Virus-induced gene silencing: empowering genetics in non-model organisms. In: Journal of experimental botany 70 (3), S. 757-770. DOI: 10.1093/jxb/ery411.

11. Filiault, Danièle L.; Ballerini, Evangeline S.; Mandáková, Terezie; Aköz, Gökçe; Derieg, Nathan J.; Schmutz, Jeremy et al. (2018): The Aquilegia genome provides insight into adaptive radiation and reveals an extraordinarily polymorphic chromosome with a unique history. In: eLife 7. DOI: 10.7554/eLife.36426.

12. Guo, Li; Winzer, Thilo; Yang, Xiaofei; Li, Yi; Ning, Zemin; He, Zhesi et al. (2018): The opium poppy genome and morphinan production. In: Science (New York, N.Y.) 362 (6412), S. 343-347. DOI: 10.1126/science.aat4096.

13. Hayashi, Shunya; Watanabe, Mutsumi; Kobayashi, Makoto; Tohge, Takayuki; Hashimoto, Takashi; Shoji, Tsubasa (2020): Genetic Manipulation of Transcriptional Regulators Alters Nicotine Biosynthesis in Tobacco. In: Plant \& cell physiology 61 (6), S. 1041-1053. DOI: 10.1093/pcp/pcaa036. 
14. Hickman JC (1993) The Jepson manual: higher plants of California. California: University of California Press. 1424 p.

15. Hisiger, Steve; Jolicoeur, Mario (2005): Plant cell culture monitoring using an in situ multiwavelength fluorescence probe. In: Biotechnology progress 21 (2), S. 580-589. DOI: 10.1021/bp049726f.

16. Hori, Kentaro; Yamada, Yasuyuki; Purwanto, Ratmoyo; Minakuchi, Yohei; Toyoda, Atsushi; Hirakawa, Hideki; Sato, Fumihiko (2018): Mining of the Uncharacterized Cytochrome P450 Genes Involved in Alkaloid Biosynthesis in California Poppy Using a Draft Genome Sequence. In: Plant \& cell physiology 59 (2), S. 222-233. DOI: 10.1093/pcp/pcx210.

17. Isoda, Reika; Yoshinari, Akira; Ishikawa, Yuuma; Sadoine, Mayuri; Simon, Rüdiger; Frommer, Wolf B.; Nakamura, Masayoshi (2021): Sensors for the quantification, localization and analysis of the dynamics of plant hormones. In: The Plant journal : for cell and molecular biology 105 (2), S. 542-557. DOI: 10.1111/tpj.15096.

18. Lampropoulos, Athanasios; Sutikovic, Zoran; Wenzl, Christian; Maegele, Ira; Lohmann, Jan U.; Forner, Joachim (2013): GreenGate--a novel, versatile, and efficient cloning system for plant transgenesis. In: PloS one 8 (12), e83043. DOI: 10.1371/journal.pone.0083043.

19. Lange, Matthias; Yellina, Aravinda L.; Orashakova, Svetlana; Becker, Annette (2013): Virus-induced gene silencing (VIGS) in plants: an overview of target species and the virus-derived vector systems. In: Methods in molecular biology (Clifton, N.J.) 975, S. 1-14. DOI: 10.1007/978-1-62703-278-0_1.

20. Leger, E. A.; Rice, K. J. (2007): Assessing the speed and predictability of local adaptation in invasive California poppies (Eschscholzia californica). In: Journal of evolutionary biology 20 (3), S. 1090-1103. DOI: 10.1111/j.14209101.2006.01292.x.

21. Li, Yi; Winzer, Thilo; He, Zhesi; Graham, lan A. (2020): Over 100 Million Years of Enzyme Evolution Underpinning the Production of Morphine in the Papaveraceae Family of Flowering Plants. In: Plant communications 1 (2), S. 100029. DOI: $10.1016 /$ j.xplc.2020.100029.

22. Liu, Xiubin; Liu, Yisong; Huang, Peng; Ma, Yongshuo; Qing, Zhixing; Tang, Qi et al. (2017): The Genome of Medicinal Plant Macleaya cordata Provides New Insights into Benzylisoquinoline Alkaloids Metabolism. In: Molecular plant 10 (7), S. 975-989. DOI: 10.1016/j.molp.2017.05.007.

23. Magallón, Susana; Gómez-Acevedo, Sandra; Sánchez-Reyes, Luna L.; Hernández-Hernández, Tania (2015): A metacalibrated time-tree documents the early rise of flowering plant phylogenetic diversity. In: The New phytologist 207 (2), S. 437-453. DOI: 10.1111/nph.13264.

24. Möller, Ralf; Ball, Roderick D.; Henderson, Anna R.; Modzel, Günter; Find, Jens (2006): Effect of Light and Activated Charcoal on Tracheary Element Differentiation in Callus Cultures of Pinus Radiata D. Don. In: Plant Cell Tiss Organ Cult 85 (2), S. 161-171. DOI: 10.1007/s11240-005-9065-z.

25. Orashakova, Svetlana; Lange, Matthias; Lange, Sabrina; Wege, Stefanie; Becker, Annette (2009): The CRABS CLAW ortholog from California poppy (Eschscholzia californica, Papaveraceae), EcCRC, is involved in floral meristem termination, gynoecium differentiation and ovule initiation. In: The Plant journal : for cell and molecular biology 58 (4), S. 682-693. DOI: 10.1111/j.1365-313X.2009.03807.x.

26. Park, Sang-Un; Facchini, Peter J. (2000a): Agrobacterium-mediated transformation of opium poppy, Papaver somniferum, via shoot organogenesis. In: Journal of Plant Physiology 157 (2), S. 207-214. DOI: 10.1016/S01761617(00)80192-3.

27. Park, S-U; Facchini, P. J. (2000b): Agrobacterium-mediated genetic transformation of California poppy, Eschscholzia californica Cham., via somatic embryogenesis. In: Plant cell reports 19 (10), S. 1006-1012. DOI:

$10.1007 / \mathrm{s} 002990000213$. 
28. Park, S-U; Facchini, P. J. (2000c): High-efficiency somatic embryogenesis and plant regeneration in California poppy, Eschscholzia californica Cham. In: Plant cell reports 19 (4), S. 421-426. DOI: 10.1007/s002990050750.

29. Peña-Gómez, Francisco T.; Guerrero, Pablo C.; Bizama, Gustavo; Duarte, Milén; Bustamante, Ramiro O. (2014): Climatic niche conservatism and biogeographical non-equilibrium in Eschscholzia californica (Papaveraceae), an invasive plant in the Chilean Mediterranean region. In: PloS one 9 (8), e105025. DOI: 10.1371/journal.pone.0105025.

30. Popelka, Juan Carlos; Xu, Jianping; Altpeter, Fredy (2003): Generation of rye (Secale cereale L.) plants with low transgene copy number after biolistic gene transfer and production of instantly marker-free transgenic rye. In: Transgenic research 12 (5), S. 587-596. DOI: 10.1023/a:1025822731661.

31. Shan, Qiwei; Wang, Yanpeng; Li, Jun; Gao, Caixia (2014): Genome editing in rice and wheat using the CRISPR/Cas system. In: Nature protocols 9 (10), S. 2395-2410. DOI: 10.1038/nprot.2014.157.

32. Stebbins, G.L. (1965). Colonizing species of the native California flora. In: The Genetics of Colonizing Species (eds Baker, H.G. \& Stebbins G.L.). Academic Press, New York.

33. Thomas, T. Dennis (2008): The role of activated charcoal in plant tissue culture. In: Biotechnology advances 26 (6), S. 618-631. DOI: 10.1016/j.biotechadv.2008.08.003.

34. Viehweger, Katrin; Schwartze, Wieland; Schumann, Brigitte; Lein, Wolfgang; Roos, Werner (2006): The Galpha protein controls a pH-dependent signal path to the induction of phytoalexin biosynthesis in Eschscholzia californica. In: The Plant cell 18 (6), S. 1510-1523. DOI: 10.1105/tpc.105.035121.

35. Wege, Stefanie; Scholz, Andrea; Gleissberg, Stefan; Becker, Annette (2007): Highly efficient virus-induced gene silencing (VIGS) in California poppy (Eschscholzia californica): an evaluation of VIGS as a strategy to obtain functional data from non-model plants. In: Annals of botany 100 (3), S. 641-649. DOI: 10.1093/aob/mcm118.

36. Wreath, Sara; Bartholmes, Conny; Hidalgo, Oriane; Scholz, Andrea; Gleissberg, Stefan (2013): Silencing of EcFLO, A FLORICAULA/LEAFY Gene of the California Poppy (Eschscholzia californica ), Affects Flower Specification in a Perigynous Flower Context. In: International Journal of Plant Sciences 174 (2), S. 139-153. DOI: 10.1086/668787.

37. Yamada, Yasuyuki; Hirakawa, Hideki; Hori, Kentaro; Minakuchi, Yohei; Toyoda, Atsushi; Shitan, Nobukazu; Sato, Fumihiko (2021): Comparative analysis using the draft genome sequence of California poppy (Eschscholzia californica) for exploring the candidate genes involved in benzylisoquinoline alkaloid biosynthesis. In: Bioscience, biotechnology, and biochemistry 85 (4), S. 851-859. DOI: 10.1093/bbb/zbaa091.

38. Yamada, Yasuyuki; Nishida, Shohei; Shitan, Nobukazu; Sato, Fumihiko (2020): Genome-wide identification of AP2/ERF transcription factor-encoding genes in California poppy (Eschscholzia californica) and their expression profiles in response to methyl jasmonate. In: Scientific reports 10 (1), S. 18066. DOI: 10.1038/s41598-020-75069-7.

39. Yamada, Yasuyuki; Shimada, Tomoe; Motomura, Yukiya; Sato, Fumihiko (2017): Modulation of benzylisoquinoline alkaloid biosynthesis by heterologous expression of CjWRKY1 in Eschscholzia californica cells. In: PloS one 12 (10), e0186953. DOI: 10.1371/journal.pone.0186953.

40. Yoshimatsu, K.; Shimomura, K. (1992): Transformation of opium poppy (Papaver somniferum L.) with Agrobacterium rhizogenes MAFF 03-01724. In: Plant cell reports 11 (3), S. 132-136. DOI: 10.1007/BF00232165.

41. Zhao, Yafei; Pfannebecker, Kai; Dommes, Anna Barbara; Hidalgo, Oriane; Becker, Annette; Elomaa, Paula (2018): Evolutionary diversification of CYC/TB1-like TCP homologs and their recruitment for the control of branching and floral morphology in Papaveraceae (basal eudicots). In: The New phytologist 220 (1), S. 317-331. DOI: 10.1111/nph.15289.

42. Zhou, Jun; Hunter, Donald A.; Lewis, David H.; McManus, Michael T.; Zhang, Huaibi (2018): Insights into carotenoid accumulation using VIGS to block different steps of carotenoid biosynthesis in petals of California poppy. In: Plant cell reports 37 (9), S. 1311-1323. DOI: 10.1007/s00299-018-2314-5.

Page $11 / 16$ 
Tables

Table 1

Callus regeneration rate dependent on different E. californica organ explants and varying concentrations of 2,4 D, NAA, BAP and $0.5 \mathrm{~g} / \mathrm{l}$ activated charcoal

\begin{tabular}{|c|c|c|c|c|c|c|c|c|c|c|}
\hline \multicolumn{5}{|c|}{ Cotyledons as explants for callus production } & \multicolumn{6}{|c|}{ Cotyledons as explants for callus production } \\
\hline $\begin{array}{l}\mathrm{mg} / \mathrm{l} \\
2,4- \\
\mathrm{D}\end{array}$ & $\begin{array}{l}\text { total } \\
\text { number }\end{array}$ & callus & $\begin{array}{l}\text { dead } \\
\text { tissue }\end{array}$ & $\begin{array}{l}\text { callus } \\
\text { regeneration }\end{array}$ & $\begin{array}{l}\mathrm{mg} / \mathrm{l} 2.4- \\
\mathrm{D}+ \\
\text { activated } \\
\text { charcoal }\end{array}$ & $\begin{array}{l}\text { total } \\
\text { number }\end{array}$ & callus & $\begin{array}{l}\text { dead } \\
\text { tissue }\end{array}$ & \multicolumn{2}{|c|}{ callus regeneration } \\
\hline 0.5 & 8 & 4 & 4 & $50.00 \%$ & 0.5 & 8 & 1 & 7 & \multicolumn{2}{|c|}{$12.50 \%$} \\
\hline 1 & 13 & 3 & 10 & $23.08 \%$ & 1 & 8 & 2 & 6 & \multicolumn{2}{|c|}{$25.00 \%$} \\
\hline 1.5 & 5 & 4 & 1 & $80.00 \%$ & 1.5 & 5 & 0 & 5 & \multicolumn{2}{|c|}{$0.00 \%$} \\
\hline 2 & 5 & 1 & 4 & $20.00 \%$ & 2 & 4 & 0 & 4 & \multicolumn{2}{|c|}{$0.00 \%$} \\
\hline 3 & 6 & 4 & 2 & $66.67 \%$ & 3 & 4 & 1 & 3 & \multicolumn{2}{|c|}{$25.00 \%$} \\
\hline \multicolumn{5}{|c|}{ Hypocotyls as explants for callus production } & \multicolumn{6}{|c|}{ Hypocotyls as explants for callus production } \\
\hline $\begin{array}{l}\mathrm{mg} / \mathrm{l} \\
2,4- \\
\mathrm{D}\end{array}$ & $\begin{array}{l}\text { total } \\
\text { number }\end{array}$ & callus & $\begin{array}{l}\text { dead } \\
\text { tissue }\end{array}$ & $\begin{array}{l}\text { callus } \\
\text { regeneration }\end{array}$ & $\begin{array}{l}\mathrm{mg} / \mathrm{l} 2.4- \\
\mathrm{D}+ \\
\text { activated } \\
\text { charcoal }\end{array}$ & $\begin{array}{l}\text { total } \\
\text { number }\end{array}$ & callus & $\begin{array}{l}\text { dead } \\
\text { tissue }\end{array}$ & \multicolumn{2}{|c|}{ callus regeneration } \\
\hline 0.5 & 7 & 5 & 2 & $71.43 \%$ & 0.5 & 9 & 0 & 9 & \multicolumn{2}{|c|}{$0.00 \%$} \\
\hline 1 & 4 & 4 & 0 & $100.00 \%$ & 1 & 3 & 1 & 2 & \multicolumn{2}{|c|}{$33.33 \%$} \\
\hline 1.5 & 5 & 3 & 2 & $60.00 \%$ & 1.5 & 5 & 1 & 4 & \multicolumn{2}{|c|}{$20.00 \%$} \\
\hline 2 & 4 & 4 & 0 & $100.00 \%$ & 2 & 2 & 0 & 2 & \multicolumn{2}{|c|}{$0.00 \%$} \\
\hline 3 & 7 & 7 & 0 & $100.00 \%$ & 3 & 4 & 0 & 4 & \multicolumn{2}{|c|}{$0.00 \%$} \\
\hline \multicolumn{5}{|c|}{ Unripe seeds as explants for callus production } & \multicolumn{6}{|c|}{ Somatic embryos as source for callus production } \\
\hline & $\begin{array}{l}\text { total } \\
\text { number }\end{array}$ & callus & $\begin{array}{l}\text { dead } \\
\text { tissue }\end{array}$ & $\begin{array}{l}\text { callus } \\
\text { regeneration }\end{array}$ & & $\begin{array}{l}\text { total } \\
\text { number }\end{array}$ & callus & $\begin{array}{l}\text { new } \\
\text { SEs }\end{array}$ & $\begin{array}{l}\text { root } \\
\text { hair }\end{array}$ & $\begin{array}{l}\text { callus } \\
\text { regeneration }\end{array}$ \\
\hline $\begin{array}{l}1 \\
\mathrm{mg} / \mathrm{I} \\
2.4- \\
\mathrm{D}\end{array}$ & 310 & 70 & 240 & $22.58 \%$ & $\begin{array}{l}1 \mathrm{mg} / \mathrm{l} \\
2.4-\mathrm{D}\end{array}$ & 26 & 24 & 7 & - & $92.31 \%$ \\
\hline $\begin{array}{l}2 \\
\mathrm{mg} / \mathrm{l} \\
\mathrm{NAA} \\
+0.1 \\
\mathrm{mg} / \mathrm{l} \\
\mathrm{BAP}\end{array}$ & 204 & 81 & 123 & $39.71 \%$ & $\begin{array}{l}2 \mathrm{mg} / \mathrm{l} \\
\mathrm{NAA}+ \\
0.1 \mathrm{mg} / \mathrm{l} \\
\text { BAP }+ \\
\text { activated } \\
\text { charcoal }\end{array}$ & 24 & 7 & 23 & 9 & $29.17 \%$ \\
\hline
\end{tabular}

\section{Figures}



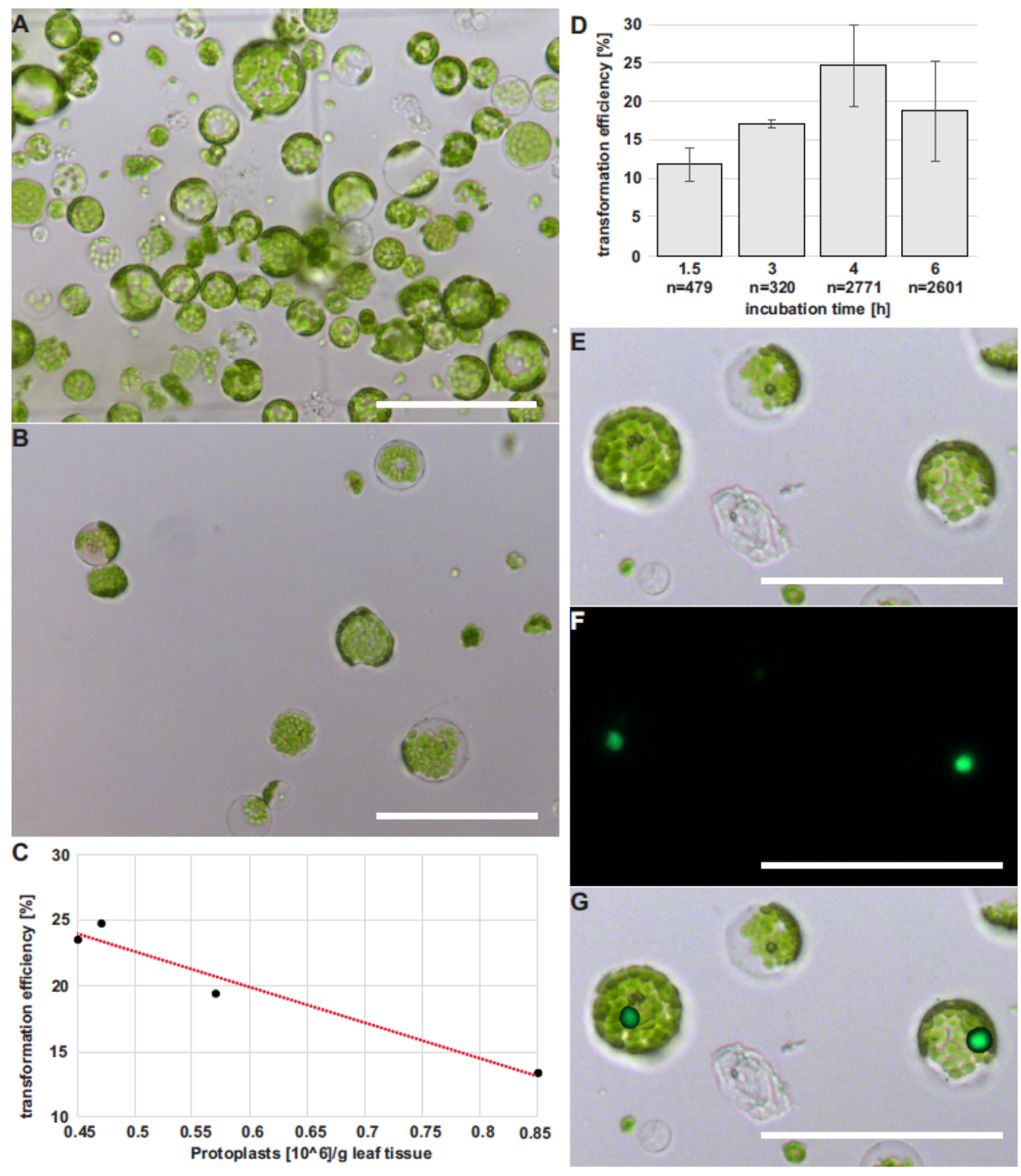

\section{Figure 1}

Protoplast isolation and transformation. Morphology of freshly isolated E. californica leaf (A) and hypocotyl (B) protoplasts. (C) Protoplast isolation efficiency in relation to the percentage of pUBQ10:GFP:NLS carrying, fluorescing protoplasts. (D) Incubation time in cell-wall dissolving enzyme solution affects transformation efficiency. Bars represent standard deviation, based on at least five independent repetitions. (E) Protoplasts transformed with pUBQ10:GFP:NLS in brightfield, fluorescence (F), and overlay (G). Size bars are $100 \mu \mathrm{m}$. 


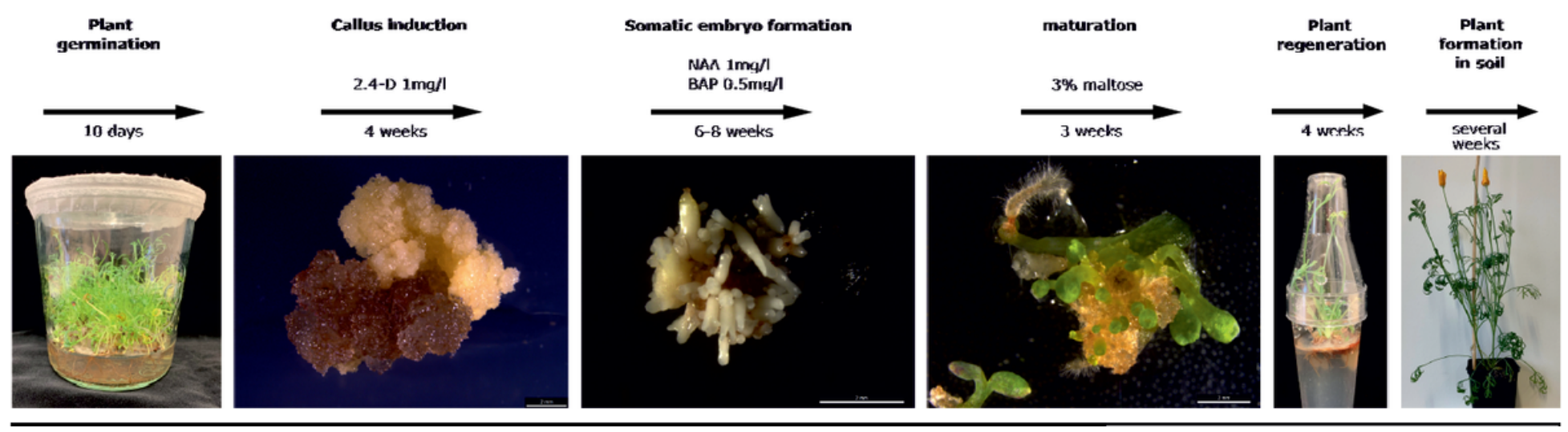

\section{Figure 2}

Time scale of plant regeneration from E. californica hypocotyl explants. Hypocotyl of 10 days old E. californica plants was used to induce callus growth on callus medium. After 6 - 8 weeks in the dark at $25^{\circ} \mathrm{C}$, regenerated callus cells were transferred to somatic embryo induction medium. For embryo maturation, regenerated embryos were transferred for three weeks to maturation medium. After maturation, all embryos were incubated in long day conditions (16h light $8 \mathrm{~h}$ dark) on plant regeneration medium without hormones. Regenerated plants were transferred to soil, covered with a cap for two weeks, to maintain humidity. 


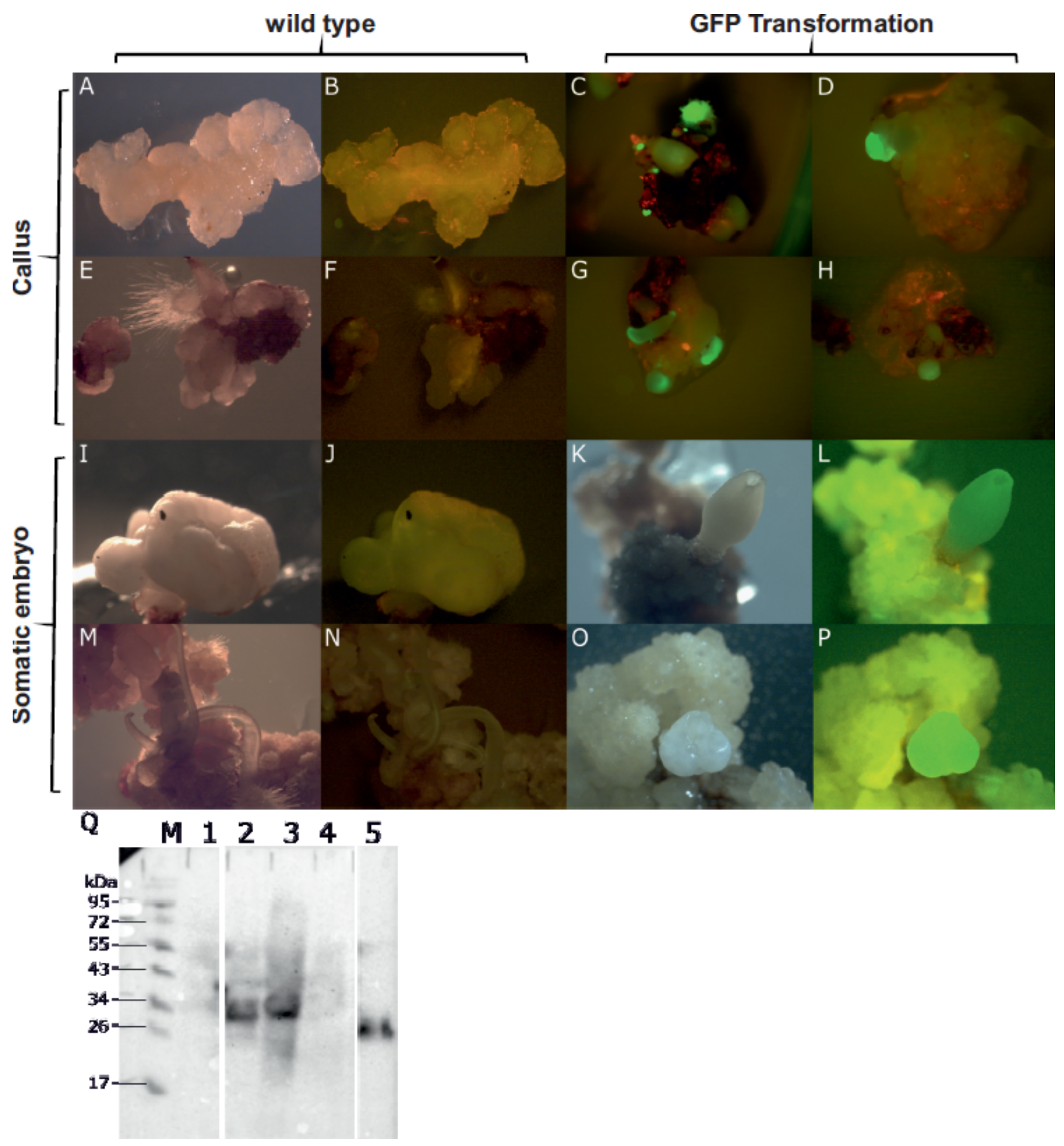

Figure 3

Documentation of transformed $\mathrm{E}$. californica plants during regeneration. A-H shows examples of growing calli. A) and E), mock-treated calli in bright field. B) and F), same calli under fluorescent light. C), D), G) and H), calli transformed with 35S:GFP under fluorescent light. I) and M), mock-treated somatic embryos in bright field, J) and N) same embryos in fluorescent light. K) and O, calli and somatic embryos carrying 35S:GFP in bright field, L) and P) same tissues in fluorescent light. Q) Western blot analysis of transgenic E. californica tissue1) wild type callus, 2) callus carrying 35S:GFP, 3) somatic embryos carrying 35S:GFP, 4) mixed sample from young regenerated plants and somatic embryos, 5) GFP antibody positive control: tobacco leaves Agrobacterium-infiltrated with HA-GFP tag that were previously analyzed to express GFP.

\section{Supplementary Files}


This is a list of supplementary files associated with this preprint. Click to download.

- OnlineResource1Supplementalfigures1KEABDL.docx

- OnlineResource2SupplementaltablesKEDLABABDL.docx

- OnlineResource3SupplementalMaterialProtocol11Aug2021.docx 